\title{
Landscape complexity is not a major trigger of species richness and food web structure of European cereal aphid parasitoids
}

\author{
Violetta Hawro • Piotr Ceryngier • Teja Tscharntke • Carsten Thies • \\ Vesna Gagic · Jan Bengtsson · Riccardo Bommarco • Camilla Winqvist • \\ Wolfgang W. Weisser · Lars W. Clement • George Japoshvili · Werner Ulrich
}

Received: 9 October 2013/ Accepted: 29 January 2015/Published online: 7 February 2015

(C) The Author(s) 2015. This article is published with open access at Springerlink.com

\begin{abstract}
In fragmented farmland landscapes structural complexity and low agricultural intensification should decrease the abundance of crop aphids due to increased abundances and species diversity of aphid enemies, including hymenopteran parasitoids. Here we study the effects of landscape structure and agricultural intensification on parasitism rates, abundances, and species richness of aphids and their parasitoids in five different regions in Europe. While total aphid numbers did not differ significantly among regions, we observed marked differences between Scandinavian and central European sites with respect
\end{abstract}

Handling Editor: Arne Janssen.

Electronic supplementary material The online version of this article (doi:10.1007/s10526-015-9660-9) contains supplementary material, which is available to authorized users.

V. Hawro $(\bowtie)$

Museum and Institute of Zoology, Polish Academy of

Sciences, Wilcza 64, 00-679 Warsaw, Poland

e-mail: violahawro@yahoo.com

P. Ceryngier

Faculty of Biology and Environmental Sciences, Cardinal

Stefan Wyszynski University, Wóycickiego 1/3,

01-938 Warsaw, Poland

T. Tscharntke $\cdot$ C. Thies · V. Gagic

Agroecology, Department of Crop Science, Georg-

August-University, Waldweg 26, 37073 Göttingen,

Germany to the species composition of aphids and their parasitoids and parasitism rates. In the cross country comparison landscape complexity and agricultural intensification did not significantly affect total aphid densities, although we observed species-specific reactions to land use. We also observed a tendency towards increased parasitoid species richness at low agricultural intensification but not at high landscape structure.

Keywords Landscape ecology · Aphid parasitoids · Aphididae $\cdot$ Cereal crops $\cdot$ Biological control

\section{Introduction}

Landscape complexity increases species richness of many animal taxa, such as birds (Geiger et al. 2010a), bees (Holzschuh et al. 2008), spiders (Schmidt et al.

\footnotetext{
V. Gagic · J. Bengtsson - R. Bommarco - C. Winqvist Department of Ecology, Swedish University of Agricultural Sciences, P.O. Box 7044, 75007 Uppsala, Sweden

W. W. Weisser

Terrestrial Ecology Research Group, Department of Ecology and Ecosystem Management, School of Life and Food Sciences Weihenstephan, Technische Universität München, Hans-Carl-von-Carlowitz-Platz 2, 85354 Freising, Germany
} 
2005), and ground beetles (Purtauf et al. 2005a, b). A number of studies also reported landscape complexity to differentially affect proportions of polyphagous and monophagous species (Jonsen and Fahrig 1997; Kassen 2002; Batáry et al. 2007). Richness of polyphagous species was found to decline at lower levels of landscape structure.

Aphids (Bianchi et al. 2006; Tscharntke et al. 2007) as well as their hymenopteran parasitoids (Landis et al. 2000; Schmidt et al. 2005; Thies et al. 2005; Tscharntke et al. 2005) are two taxa heavily influenced by landscape structure. A number of authors have argued that diverse landscapes have a higher aphid and parasitoid biodiversity than homogeneous ones (Schmidt et al. 2005; Tscharntke et al. 2005; Holland et al. 2008). Other authors argued that the occurrence of species-rich guilds of aphid natural enemies is promoted by the diversity of noncrop habitats around cereal fields (Pankanin-Franczyk 1994; Schmidt et al. 2005; Thies et al. 2011). Consequently, higher complexity of rural landscape is considered an important factor promoting the effectiveness of aphid parasitoids (Kruess and Tscharntke 2000). Additionally, parasitoid colonization and, therefore, parasitism rates are also affected by the distance between local host aphid populations and the size of aphid colonies, suggesting that spatial processes are important in this system (Rauch and Weisser 2007; Pareja et al. 2008).

Another critical determinant of effectiveness of aphid biocontrol is the ratio of polyphagous (generalist) to oligo- or monophagous (specialist) species within the different enemy guilds. Contrary to the common opinion on the superiority of specialists as biocontrol agents, generalist natural enemies such as spiders, can limit aphids more effectively because of their earlier appearance in crop fields during the

L. W. Clement

Institute of Ecology, Friedrich-Schiller-University Jena, Dornburger Str. 159, 07743 Jena, Germany

\section{G. Japoshvili}

Entomology and Biocontrol Research Centre, Agricultural University of Georgia, David Agmashenebeli Alley 13 km, 0159 Tbilisi, Georgia

W. Ulrich

Chair of Ecology and Evolutione, Nicolaus Copernicus University in Toruń, Lwowska 1, 87-100 Toruń, Poland growing season (Settle et al. 1996; Snyder and Ives 2003).

Primary and secondary parasitoids have been less frequently involved in specialist-generalist comparisons within and between trophic levels (Snyder and Ives 2003; Brewer and Elliott 2004). With few exceptions, primary hymenopteran aphid parasitoids are host specialists (Mackauer and Starý 1967; Stilmant et al. 2008). For example, Aphidius uzbekistanicus (Luzhetski) and A. rhopalosyphi (DeStefaniPeres) are mostly restricted to cereal aphids Sitobion avenae (F.), Rhopalosiphum padi (L.) and $\mathrm{Me}$ topolophium dirhodum (Walker). Some other parasitoid species have a broader host range. For instance, Ephedrus plagiator (Nees) and Praon volucre (Haliday) attack aphids associated with forest edges and orchards, but they can also attack aphids on herbaceous plants (Ölmez and Ulusoy 2003; Rakhshani et al. 2006). Therefore, more complex landscapes, consisting of forest and semi-natural habitats should provide more alternative hosts for polyphagous primary parasitoids. In turn, secondary parasitoids are mainly host generalists and are divided into more specialized true hyperparasitoids and polyphagous "pseudohyperparasitoids" (mummy parasitoids) (Müller et al. 1999). The ratio of specialists to generalists in both groups of secondary aphid parasitoids may be another important factor for biocontrol effectiveness. For example, Monmany and Aide (2009) found higher parasitism rates of herbivorous insects in some Argentinian forests as a result of higher numbers of generalist primary parasitoids. These differences between and within guild, as well as landscape structure and agricultural intensification might influence food chain structure and therefore total parasitism rates and biocontrol effectiveness (Mackauer and Völkl 1993).

Higher landscape complexity and its associated higher proportions of generalist parasitoids might increase the effectiveness of parasitoids in biocontrol. In this respect, complex landscapes and low agricultural intensification might (1) increase abundance and species richness of parasitoids in general (Fahrig et al. 2011), (2) increase parasitism rates by primary parasitoids (Thies et al. 2003; Rand et al. 2012), and (3) favor polyphagous primary parasitoids and mummy parasitoids (Jonsen and Fahrig 1997).

To date, no published study has tested these hypotheses simultaneously. Therefore, it is still 
unknown how the trade-offs between heterogeneity, species richness, and species host preferences influence parasitism rates and, therefore, crop protection. Using spatially explicit data on parasitoid attack on crop aphids from five European regions with different environmental conditions and species composition of aphids and their parasitoids, we investigated if and how species richness of parasitoids, their abundance, host range, and parasitism rates were linked to landscape complexity and agricultural intensification. This study design allowed us to disentangle the effects of landscape and food chain structure on crop protection.

\section{Materials and methods}

In 2008 in each of five European regions (Göttingen and Jena, Germany; Warsaw, Poland; Uppsala and Skåne, Sweden) (Supplementary data Fig. S1) eight cereal fields were chosen, of which four were managed at low levels of agricultural intensification and located in structurally complex landscapes, and four at high levels of agricultural intensification in simple landscapes. Fields were a minimum of one hectare, located at least one kilometer apart (Supplementary data table S2). Each of the five study areas was between $30 \times 30 \mathrm{~km}^{2}$ and $50 \times 50 \mathrm{~km}^{2}$ to minimize differences in the regional species pools among farms within each area (Geiger et al. 2010a, b). Winter wheat (Triticum aestivum L.) grew on the German and Polish sites and spring barley (Hordeum vulgare L.) in Sweden. These two crops were found to have a similar species composition of aphids and their parasitoids (Sigsgaard 2002). Sampling was synchronized between regions using phenological stages of cereals.

In this study, we used the classification of Geiger et al. (2010a, b), who estimated the degree of agricultural intensification of fields within thirty farms per region by pesticide and fertilizer use, the number of soil disrupting management events, cereal yield, the percentage of arable land and the Shannon index of habitat diversity in surrounding landscapes. The thirty fields were ranked according to these parameters, values of which were related to the particular rank. Subsequently, we summed all ranks to obtain the final rank for each field. From among these 30 fields, we selected the four fields with the highest ranks and the four lowest ranked fields. As recommended by Thies et al. (2003) landscape structure was quantified as the proportion of individual habitat types (grassland, forest and arable land) at two spatial scales: within a circle of $500 \mathrm{~m}$ radius (area of about 78.5 ha included) and within a circle of $1,000 \mathrm{~m}$ radius (about $314 \mathrm{ha}$ ) around each focal field.

Data on the abundance and species composition of aphids came from field counts of aphids on 20 randomly chosen cereal shoots at five sampling points, along a transect going from the edge to the center of each field (100 cereal shoots in total per field). Counting was done twice, at flowering and milk ripening stages of the cereals, i.e. at phenological stages following colonization of the crops by aphids and the main period of aphid reproduction, respectively (for details see Thies et al. 2005).

The species composition and abundance of aphid parasitoids were assessed from aphid mummies, collected at random in the whole field, during twohour surveys at the milk ripening stage of the crop. Mummies were taken to the laboratory and kept individually in small vials. After emergence, adult parasitoids were identified to species level. Among all sites we found only two species with single occurrences (Supplementary data table $\mathrm{S} 1$ ), indicating that our surveys were sufficiently complete to focus on observed species richness without the need for additional richness estimation.

Parasitism rate was calculated in each field at both phenological stages (cereal flowering and milk ripening) as the proportion of mummified aphids to the total number of aphids (living and mummified) on 100 cereal shoots (the same as above). Rates of hyperparasitism and mummy parasitism were calculated as the proportion of secondary parasitoids (hyperparasitoids and mummy parasitoids, respectively) to all parasitoids hatched from mummies collected during $2 \mathrm{~h}$ at milk ripening stage of the crop.

Because the error structures of our data did not significantly deviate from a normal approximation we used one-way analysis of variance (ANOVA) and general linear model analysis of covariance (ANCOVA as implemented in Statistica 9.0) to relate landscape complexity, region, and agricultural intensification to aphid abundance and parasitism rates. Pair-wise comparisons were based on Tukey post-hoc tests. The region of Uppsala (at both scales) and Skåne (solely at the $1000 \mathrm{~m}$ scale) were the only regions where agricultural intensification and landscape 
heterogeneity were dependent (ANOVA: $\mathrm{F}_{1,6}=12.2$, $\mathrm{P}<0.05$ for Skåne at $1000 \mathrm{~m}$ scale; $\mathrm{F}_{1,6}=116.7$ and 232 for Uppsala at 500 and $1000 \mathrm{~m}$ scale respectively, both $\mathrm{P}<0.01$ ). In most cases such relationships were not significant. Therefore, we treated agricultural intensification and landscape structure as independent variables.

\section{Results}

In total we recorded 11 primary parasitoid species, four hyperparasitoid and seven mummy parasitoid species, of which Aphelinus abdominalis (Dalman) and Alloxysta macrophadna (Hartig) were found only once (Supplementary data table S1). In the Jena region, primary parasitoid richness was lowest with the overwhelming dominance of a polyphagous Ephedrus species. A specialized Aphelinus sp. was exclusively restricted to the Swedish regions whilst Ephedrus sp. and Praon sp. were quite rare there. The abundance of the specialist Aphidius sp. was similar in the fields of Warsaw, Göttingen and Skåne (ANOVA: $\mathrm{F}_{2,21}=0.31, \mathrm{P}>0.05$ ) (Fig. 1; Supplementary data table S1). Richness and abundance of hyperparasitoids were highest in Skåne (Tukey post-hoc test: $\mathrm{P}<0.01$ for both variables), and lowest in the regions of Jena and Uppsala (Tukey post-hoc test: $\mathrm{P}<0.05$ for both regions). The Uppsala was also the only region where mummy parasitoids were not recorded at all (Fig. 2; Supplementary data tables S1, S3).

The common cereal aphid species $S$. avenae, $R$. padi and $M$. dirhodum occurred at all study sites (Supplementary data tables $\mathrm{S} 1, \mathrm{~S} 3$ ) but differed significantly in

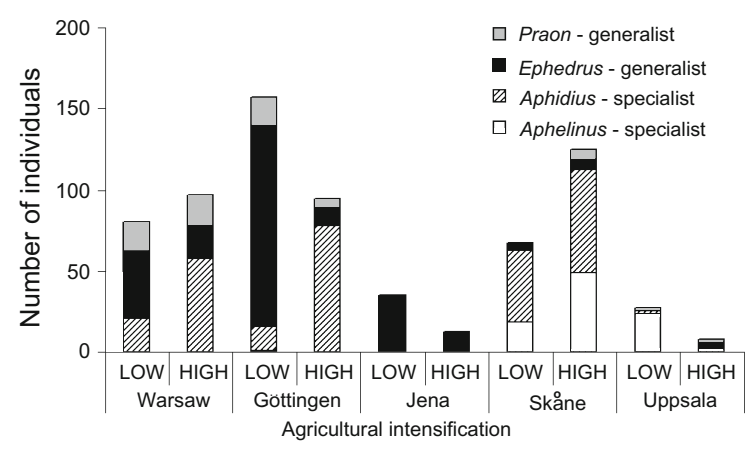

Fig. 1 Numbers of individuals of particular genera of primary parasitoids recorded in the eight study fields, with low and high agricultural intensification in each region abundance among our study regions (Table 1, Supplementary data table S4, ANOVA: $\mathrm{F}_{4,35}=10.4$ and 9.3 for $S$. avenae flowering and milk ripening stage of cereal, respectively, both at $\mathrm{P}<0.0001 ; \mathrm{F}_{4,35}=5.8$, $\mathrm{P}<0.01$ for $M$. dirhodum at cereal flowering; $\mathrm{F}$ $4,35=3.2$ and 2.6 for $R$. padi at cereal flowering and milk ripening, respectively, both at $\mathrm{P}<0.05$ ). In the two Swedish regions, $R$. padi clearly dominated at both aphid censuses, while in Göttingen and Jena the most abundant species were $S$. avenae and $M$. dirhodum, respectively. In the Warsaw region, $S$. avenae and $M$. dirhodum co-dominated attaining similar population levels. In all but one region (Göttingen), aphid abundance was higher at crop flowering than at milk ripening stage (Supplementary data table S1). Total aphid numbers at flowering and milk ripening stages did not significantly differ among regions (ANOVA: $\mathrm{F}_{4,35}=1.3$ and 1.4, respectively, both at $\left.\mathrm{P}>0.05\right)$. We also found no clear relationship between species richness of primary parasitoids and landscape heterogeneity (ANCOVA: $\mathrm{F}_{1,29}=0.22$ and 0.0005 at 500 and $1000 \mathrm{~m}$ scale, respectively, both at $\mathrm{P}>0.05$ ).

We found significant, although incongruent differences in the parasitism rates of primary, mummy, and hyperparasitoids at milk ripening stage among the regions (Table 2, Supplementary data table S4). At milk ripening stage of the crop, primary parasitism was lowest in Göttingen and highest in Warsaw, hyperparasitism highest in Skåne and lowest in Jena, and mummy parasitism highest in Jena and lowest in Uppsala (Supplementary data table S1).

At both spatial scales we found only a weak indication that aphid abundances were influenced by landscape

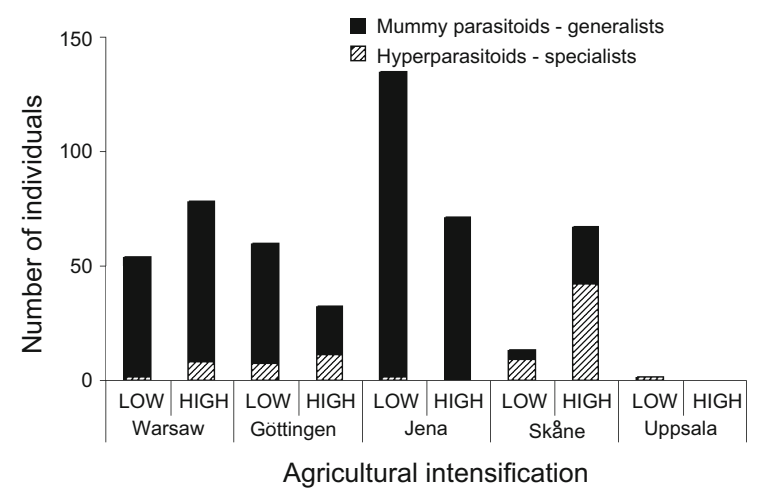

Fig. 2 Numbers of individuals of hyperparasitoids and mummy parasitoids recorded in the eight study fields, with low and high agricultural intensification in each region 
Table 1 Statistical results (ANCOVA) for the influence of landscape diversity (500 and $1000 \mathrm{~m}$ radius), region, and agricultural intensification (AI) on the abundance of particular aphid species at flowering and milk ripening stages of crop, $\mathrm{N}=40$

\begin{tabular}{|c|c|c|c|c|c|c|c|c|c|c|c|c|c|}
\hline \multirow{4}{*}{$\begin{array}{l}\text { Predictor } \\
\text { Aphid species } \\
\text { Cereal stage }\end{array}$} & \multirow{4}{*}{$\begin{array}{l}\text { df (effect, } \\
\text { error) }\end{array}$} & \multicolumn{12}{|c|}{ Abundance } \\
\hline & & \multicolumn{4}{|c|}{ Sitobion avenae } & \multicolumn{4}{|c|}{ Metopolophium dirhodum } & \multicolumn{4}{|c|}{ Rhopalosiphum padi } \\
\hline & & \multicolumn{2}{|c|}{ Flowering } & \multicolumn{2}{|c|}{ Milk ripening } & \multicolumn{2}{|c|}{ Flowering } & \multicolumn{2}{|c|}{$\begin{array}{l}\text { Milk } \\
\text { ripening }\end{array}$} & \multicolumn{2}{|c|}{ Flowering } & \multicolumn{2}{|c|}{$\begin{array}{l}\text { Milk } \\
\text { ripening }\end{array}$} \\
\hline & & $\mathrm{F}$ & $\mathrm{P}$ & $\mathrm{F}$ & $\mathrm{P}$ & $\mathrm{F}$ & $\mathrm{P}$ & $\mathrm{F}$ & $\mathrm{P}$ & $\mathrm{F}$ & $\mathrm{P}$ & $\mathrm{F}$ & $\mathrm{P}$ \\
\hline $\begin{array}{l}\text { Landscape heterogeneity } \\
500 \mathrm{~m}\end{array}$ & 1,38 & 2.13 & 0.16 & 3.21 & 0.08 & 4.12 & 0.05 & 0.04 & 0.85 & 0.58 & 0.45 & 0 & 0.98 \\
\hline Region & 4,35 & 11.16 & $<0.01$ & 11.81 & $<0.01$ & 7.71 & $<0.01$ & 0.59 & 0.67 & 3.42 & 0.02 & 2.26 & 0.09 \\
\hline AI & 1,38 & 0.5 & 0.48 & 0.18 & 0.67 & 6.78 & 0.01 & 3.08 & 0.09 & 0.99 & 0.33 & 0.23 & 0.64 \\
\hline Region $\times$ AI & 4,35 & 1.15 & 0.35 & 3.74 & 0.01 & 1.72 & 0.17 & 0.74 & 0.58 & 1.77 & 0.16 & 0.25 & 0.91 \\
\hline $\begin{array}{l}\text { Landscape heterogeneity } \\
1,000 \mathrm{~m}\end{array}$ & 1,38 & 5.02 & $\mathbf{0 . 0 3}$ & 2.29 & 0.14 & 4.16 & 0.05 & 0.23 & 0.63 & 0.27 & 0.61 & 0 & 0.98 \\
\hline Region & 4,35 & 12.14 & $<0.01$ & 9.57 & $<.01$ & 8.07 & $<0.01$ & 0.56 & 0.69 & 3.41 & 0.02 & 2.24 & 0.09 \\
\hline AI & 1,38 & 0.05 & 0.82 & 0.2 & 0.66 & 7 & 0.01 & 2.34 & 0.14 & 0.76 & 0.39 & 0.24 & 0.63 \\
\hline Region $\times$ AI & 4,35 & 1.76 & 0.16 & 3.5 & 0.02 & 1.69 & 0.18 & 0.72 & 0.58 & 1.79 & 0.16 & 0.24 & 0.91 \\
\hline$\%$ of arable land $500 \mathrm{~m}$ & 1,38 & 3.35 & 0.08 & 5.96 & 0.02 & 3.5 & 0.07 & 0 & 0.99 & 0.16 & 0.69 & 0.01 & 0.93 \\
\hline Region & 4,35 & 11.8 & $<0.01$ & 11.12 & $<0.01$ & 7.88 & $<0.01$ & 0.59 & 0.67 & 3.37 & 0.02 & 2.26 & 0.09 \\
\hline AI & 1,38 & 0.32 & 0.58 & 0.03 & 0.87 & 6.26 & 0.02 & 3.47 & 0.07 & 0.65 & 0.43 & 0.2 & 0.66 \\
\hline Region $\times$ AI & 4,35 & 1.24 & 0.32 & 4.22 & 0.01 & 1.67 & 0.18 & 0.73 & 0.58 & 1.7 & 0.18 & 0.25 & 0.91 \\
\hline$\%$ of arable land $1,000 \mathrm{~m}$ & 1,39 & 7.44 & 0.01 & 6.59 & 0.02 & 5.56 & 0.03 & 0 & 0.98 & 0.18 & 0.68 & 0.06 & 0.81 \\
\hline Region & 4,35 & 13.52 & $<0.01$ & 9.56 & $<0.01$ & 8.88 & $<0.01$ & 0.59 & 0.68 & 3.38 & 0.02 & 2.25 & 0.09 \\
\hline AI & 1,39 & 0.02 & 0.88 & 0.01 & 0.94 & 7.91 & 0.01 & 3.35 & 0.08 & 0.66 & 0.42 & 0.13 & 0.72 \\
\hline Region $\times$ AI & 4,35 & 2.04 & 0.12 & 4.76 & $<0.01$ & 1.8 & 0.16 & 0.73 & 0.58 & 1.75 & 0.17 & 0.2 & 0.94 \\
\hline
\end{tabular}

Statistically significant values of the associated F-tests $(\mathrm{P}<0.05)$ are in bold

complexity (Table 1, Supplementary data table S4). Only $S$. avenae seemed to be negatively influenced by the percentage of arable land and reached higher abundances in structurally more diverse landscapes (Tukey post-hoc test: $\mathrm{P}<0.01)$. Abundances of the aphid M. dirhodum were positively correlated with agricultural intensification (Table 1, Supplementary data table S4).

High agricultural intensification did not significantly reduce parasitoid species richness (matched pairs test: $\mathrm{P}>0.1$ ). However, there was a weak tendency to increased species numbers (Fig. 3a: six data points below and three above the 1:1 regression line, $\mathrm{P}$ (binomial distribution) $=0.25$ ) and parasitism rates (Fig. 3b: eight data points below and four above the $1: 1$ regression line, $\mathrm{P}($ binomial distribution $)=0.19$ ) at low agricultural intensification.

Parasitism rates by hyperparasitoids were independent of the rates of primary parasitoids (Fig. 4a), while parasitism rates by mummy parasitoids increased with those by primary parasitism (Fig. 4b). They were also independent of agricultural intensification and landscape structure in all cases (Table 2, Supplementary data table S4).

\section{Discussion}

Our study does not corroborate common hypotheses on the influence of landscape heterogeneity on parasitoid abundance and their effectiveness as biocontrol agents (Kruess and Tscharntke 2000; Thies et al. 2003, 2005). These hypotheses state that high primary parasitoid abundances in complex landscapes should increase parasitism rates and reduce pest numbers (Altieri and Letourneau 1982). For example Gagic et al. (2011) reported a higher rate of aphid parasitism in areas with more diverse vegetation. However some authors challenged this view, showing that complex landscape (Menalled et al. 1999) as well as the species richness of the food web (Montoya et al. 
Table 2 Statistical results (ANCOVA) for the influence of landscape diversity (500 and $1000 \mathrm{~m}$ radius), region, and agricultural intensification (AI) on parasitism rates of primary,

\begin{tabular}{|c|c|c|c|c|c|c|c|c|c|}
\hline \multirow{4}{*}{$\begin{array}{l}\text { Predictor } \\
\text { Cereal stage }\end{array}$} & \multirow[t]{4}{*}{ df (effect, error) } & \multicolumn{8}{|c|}{ Parasitism rates } \\
\hline & & \multicolumn{4}{|c|}{ Primary parasitoids } & \multirow{2}{*}{\multicolumn{2}{|c|}{$\frac{\text { Hyperparasitoids }}{\text { Milk ripening }}$}} & \multirow{2}{*}{\multicolumn{2}{|c|}{$\frac{\text { Mummy parasitoids }}{\text { Milk ripening }}$}} \\
\hline & & \multicolumn{2}{|c|}{ Flowering } & \multicolumn{2}{|c|}{ Milk ripening } & & & & \\
\hline & & $\mathrm{F}$ & $\mathrm{P}$ & $\mathrm{F}$ & $\mathrm{P}$ & $\mathrm{F}$ & $\mathrm{P}$ & $\mathrm{F}$ & $\mathrm{P}$ \\
\hline Landscape heterogeneity $500 \mathrm{~m}$ & 1,38 & 0.37 & 0.55 & 0.09 & 0.7 & 0.07 & 0.8 & 2.72 & 0.11 \\
\hline Region & 4,35 & 0.84 & 0.51 & 3.69 & 0.02 & 1.68 & 0.18 & 24.57 & $<0.01$ \\
\hline $\mathrm{AI}$ & 1,38 & 0.26 & 0.61 & 0.38 & 0.54 & 0 & 1 & 3.62 & 0.07 \\
\hline Region $\times \mathrm{AI}$ & 4,35 & 1.5 & 0.23 & 0.55 & 0.7 & 1.76 & 0.16 & 1.25 & 0.31 \\
\hline Landscape heterogeneity $1000 \mathrm{~m}$ & 1,38 & 2.94 & 0.1 & 0.26 & 0.61 & 0.1 & 0.75 & 2.25 & 0.14 \\
\hline Region & 4,35 & 0.58 & 0.68 & 3.72 & 0.01 & 1.66 & 0.19 & 24.27 & $<0.01$ \\
\hline AI & 1,38 & 1.35 & 0.26 & 0.54 & 0.47 & 0 & 0.96 & 3.41 & 0.07 \\
\hline Region $\times$ AI & 4,35 & 1.36 & 0.27 & 0.6 & 0.67 & 1.79 & 0.16 & 1.3 & 0.29 \\
\hline$\%$ of arable land $500 \mathrm{~m}$ & 1,38 & 0.7 & 0.41 & 0.09 & 0.77 & 0.04 & 0.84 & 2.1 & 0.16 \\
\hline Region & 4,35 & 0.76 & 0.56 & 3.63 & 0.02 & 1.68 & 0.18 & 24.22 & $<0.01$ \\
\hline AI & 1,38 & 0.39 & 0.54 & 0.38 & 0.54 & 0 & 0.98 & 3.19 & 0.08 \\
\hline Region $\times$ AI & 4,35 & 1.58 & 0.21 & 0.55 & 0.7 & 1.74 & 0.17 & 1.08 & 0.38 \\
\hline$\%$ of arable land $1000 \mathrm{~m}$ & 1,38 & 2.37 & 0.13 & 0.19 & 0.67 & 0 & 0.99 & 1.22 & 0.28 \\
\hline Region & 4,35 & 0.6 & 0.67 & 3.59 & 0.02 & 1.69 & 0.18 & 23.21 & $<0.01$ \\
\hline AI & 1,38 & 1.02 & 0.32 & 0.47 & 0.5 & 0.02 & 0.9 & 2.55 & 0.12 \\
\hline Region $\times$ AI & 4,35 & 1.38 & 0.26 & 0.58 & 0.68 & 1.7 & 0.18 & 1.12 & 0.37 \\
\hline
\end{tabular}

Statistically significant values of the associated F-tests $(\mathrm{P}<0.05)$ are in bold

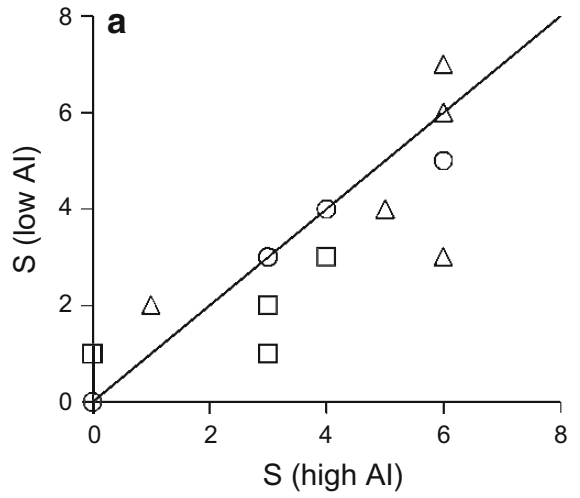

Fig. 3 Species richness $S$ (a) and parasitism rates $p(\mathbf{b})$ of primary (triangles), mummy (circles), and hyperparasitoids (squares) on fields of low and high agricultural intensification (AI) were positively correlated (a $\mathrm{r}=0.85$; permutation

2003) do not enhance rates of parasitism. Similar results were obtained by Salvo et al. (2005) who showed that parasitism and parasitoid species richness were higher in simple than in complex habitats. hyperparasitoids, and mummy parasitoids at flowering and milk ripening stages of crop, $\mathrm{N}=40$ 


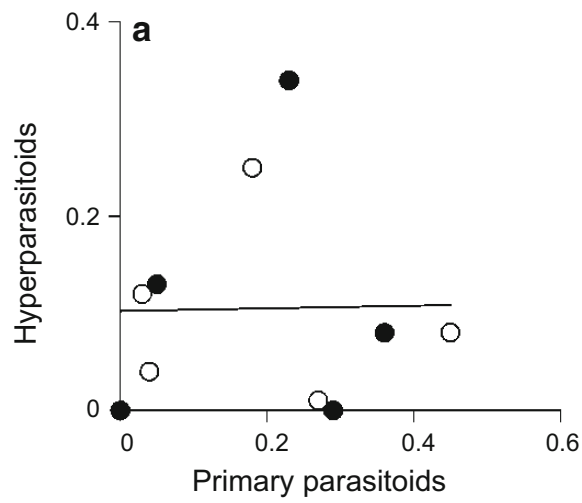

Fig. 4 Parasitism rates of hyperparasitoids were not correlated with the rates of primary parasitoids (a linear regression $\mathrm{r}=0.02$; permutation $\mathrm{P}>0.5$ ), while parasitism rates of mummy parasitoids significantly increased with those of

et al. (2008) and Rand et al. (2012), in contrast to other investigations, which have identified environmental heterogeneity as an important contributor to total species richness of different vertebrate and arthropod taxa (Kassen 2002; Schmidt et al. 2005; Bianchi et al. 2006; Öberg et al. 2007; Schüepp et al. 2011). According to previous studies, species richness of organisms was influenced particularly by the number of cover types and their spatial array (Holland and Fahrig 2000; Weibull et al. 2000), but also by the habitat age (Fahrig and Jonsen 1998; Tscharntke and Kruess 1999), land-use intensification, cropping history (Thies and Tscharntke 1999), soil variables, and climate (Dormann et al. 2008). Some authors (Gagic et al. 2011; Schüepp et al. 2011; Rand et al. 2012) have also suggested that parasitoids might benefit from the proximity of perennial herbaceous habitats and forest patches surrounding arable fields. Semi-natural habitats were found to increase the longevity and fecundity of parasitoids and offered them shelter from agricultural disturbances (Costamagna et al. 2004; Araj et al. 2008).

Our results do not point to any significant influence of landscape complexity on parasitoid species richness (see results section) and parasitism rate after accounting for differences among regions (Table 2, Supplementary data table S4). Therefore, the most likely explanation for these mixed results may be that studies have been conducted in different regions. Another explanation could be tied with temporal variation in the dynamics of parasitoids (Menalled et al. 2003), or simply the short period of the study. However, most

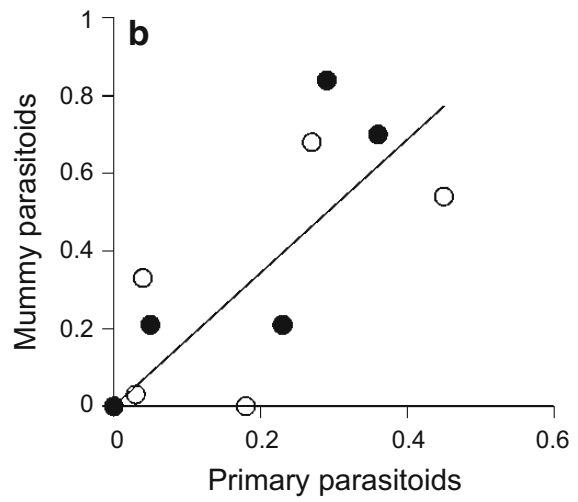

primary parasitoids (b linear regression $r=0.73$; permutation $\mathrm{P}=0.01)$. Black dots refer to high agricultural intensification (AI) fields, open circles to low AI fields

studies exploring this issue (Marino and Landis 1996; Menalled et al. 1999; Costamagna et al. 2004; Salvo et al. 2005; Monmany and Aide 2009; Gagic et al. 2011; Rand et al. 2012) lasted only one season. Moreover, some of them have tested pests that are usually controlled by generalists, rather, than more specialized parasitoids with few alternative hosts (Marino and Landis 1996; Costamagna et al. 2004; Monmany and Aide 2009). The results of this and other investigations suggest that various causes (regional differences, variability in population dynamics, duration of the studies, different studied organisms) may generate inconsistent results. Nevertheless, they concern the influence of landscape or agricultural intensification and it is justifiable to take their conclusions into account.

Our investigation strongly shows the species composition of aphids and their parasitoids, as well as the effectiveness of parasitoids as biocontrol agents, depend mainly on the geographical region, but not on the landscape heterogeneity nor on the agricultural intensification (Table 2, Supplementary data table $\mathrm{S} 4)$. For instance, R. padi is known as the most abundant cereal aphid in Sweden (Leather et al. 1989; Östaman et al. 2001). The dominance of $R$. padi is associated with better suitability for cooler climates (Gianoli 1999). This fact and the high abundance of its primary host Prunus padus may explain the increased abundances of this aphid at the Swedish study sites. The differences in species composition of aphids and their parasitoids recorded between European and Swedish study regions, were probably not caused by 
the occurrence of different host plants (Sweden spring barley, Europe - winter wheat). According to the results of Leather and Lehti (1982), R. padi was equally distributed on barley, wheat and oats in colder regions like Finland. Similar results were obtained by Sigsgaard (2002), who showed no differences in aphid and parasitoid species composition between wheat and barley in Zealand (Denmark). She recorded all three aphid species, with a strong dominance of $S$. avenae, and with very low numbers of $M$. dirhodum and $R$. padi on both host plants.

These regional differences in aphid composition affected higher trophic levels. Le Ralec et al. (2011) emphasized internal defense mechanisms of $R$. padi, which result in many of its parasitoids being unable to reach later larval stages. As the spectrum of parasitoids was limited to Aphidius and Aphelinus species at the Swedish sites, more polyphagous taxa such as Ephedrus and Praon, may not have been able to break the immunological defense of $R$. padi. In turn, Ephedrus and Praon were abundant in central Europe, where $R$. padi was not so common (Fig. 1, Supplementary data table S1).

Kassen (2002) and Schüepp et al. (2011) hypothesized that complex landscapes and low intensity agriculture favor generalist organisms. In the present case, this prediction refers particularly to polyphagous mummy parasitoids. In comparison with hyperparasitoids, they are expected to exert stronger parasitism pressure on primary parasitoids in diverse landscapes due to their higher numbers in such landscapes (Tscharntke et al. 2007). However, in comparison with specialized hyperparasitoids, polyphagous mummy parasitoids might be less effective in limiting primary parasitoids because of other hosts that they can utilize (Montoya et al. 2003). In turn, simple landscapes are expected to promote an increased proportion of specialized Aphidius and Aphelinus species within primary parasitoid assemblages. It would result in higher numbers of specialized hyperparasitoids, which prefer these species as hosts. Such a situation should weaken the primary parasitoid pressure. Again, our results do not corroborate this view. We did not find significant responses of parasitoid species richness (see results section) and parasitism rates (Fig. 3; Table 2, Supplementary data table S4) to our measures of landscape heterogeneity and agricultural intensification, as well as parasitism rates by primary, hyperparasitoids, and mummy parasitoids
(Fig. 4; Table 2, Supplementary data table S4). Furthermore, we did not observe any response of hyperparasitoids to the increased abundance of their hosts. Hyperparasitoids and primary parasitism rates were independent irrespective of agricultural intensification (Fig. 4a). In turn, mummy parasitoids increased their parasitism rates at higher levels of primary parasitoid attack (Fig. 4b), again regardless of agricultural intensification. Such a linear increase might have severe consequences for the population dynamics of the primary parasitoids and might indicate densitydependent prey mortality (Varley et al. 1974; van Veen et al. 2002). Our data do not allow for a direct test of this prediction as we did not measure parasitism rates directly. However, the correlation between mummy and primary parasitoid attack rates (Fig. 4b) is expected if parasitoid effectiveness in biological control were independent from landscape heterogeneity and agricultural intensification and mainly triggered by host availability.

In line with the above argument, landscape complexity and agricultural intensification did not significantly affect total aphid population densities in the cross country comparison although we found significant species-specific differences in regional abundance (Table 1, Supplementary data table S1). Metopolophium dirhodum seems to be affected by agricultural intensification, whilst Sitobion avenae by landscape structure (Table 1, Supplementary data table S4). The latter finding is in line with Thies et al. (2005) who showed a positive influence of landscape heterogeneity on the dominant $S$. avenae and explained this by the food preferences of $S$. avenae, and its association with grassy habitats.

In conclusion, our results did not reveal a dominant influence of landscape structure and agricultural intensification on aphid-parasitoid food webs. However, we found significant differences in abundance and species richness of aphids and their parasitoids, and parasitism rates between geographical regions across Europe. Patterns of parasitoid attack and, therefore, their effectiveness in the control of aphid crop pests appeared to be largely independent from the landscape parameters we quantified.

Acknowledgments The study is part of the AGRIPOPES project (AGRIcultural POlicy-induced landscaPe changes: effects on biodiversity and Ecosystem Services; http:// agripopes.net), funded through the European Science Foundation (EUROCORES programme), in collaboration with the 
national funding agencies, the Polish Ministry of Science and Higher Education, the German Research Foundation (DFG), the German Ministry of Education and Research (BMBF), the Swedish Research Council for Environment, Agricultural Sciences and Spatial Planning. We would like to thank Želijko Tomanović for help with identification of some parasitoid individuals, and Richard Hopkins for his help with language improvement. Special thanks to anonymous reviewers for valuable comments.

Open Access This article is distributed under the terms of the Creative Commons Attribution License which permits any use, distribution, and reproduction in any medium, provided the original author(s) and the source are credited.

\section{References}

Altieri MA, Letourneau DK (1982) Vegetation management and biological control in agroecosystems. Crop Prot 1:405-430

Araj SE, Wratten S, Lister A, Buckley H (2008) Floral diversity, parasitoids and hyperparasitoids - a laboratory approach. Basic Appl Ecol 9:588-597

Batáry P, Báldi A, Szél G, Podlussány A, Rozner I, Erdos S (2007) Responses of grassland specialist and generalist beetles management and landscape complexity. Divers Distrib 13:196-202

Bianchi FJJA, Booij CJH, Tscharntke T (2006) Sustainable pest regulation in agricultural landscapes: a review on landscape composition, biodiversity and natural pest control. Proc R Soc B 273:1715-1727

Brewer MJ, Elliott NC (2004) Biological control of cereal aphids in north America and mediating effects of host plant and habitat manipulations. Annu Rev Entomol 49:219-242

Costamagna AC, Menalled FD, Landis DA (2004) Host density influences parasitism of the armyworm Pseudaletia unipuncta in agricultural landscapes. Basic Appl Ecol 5:347-355

Dormann CF, Schweiger O, Arens P, Augenstein I, ST Aviron, Bailey D, Baudry J, Billeter R, Bugter R, Bukácek R, Burel F, Cerny M, De Cock R, De Blust G, DeFilippi R, Diekötter T, Dirksen J, Dukra W, Edwards PJ, Frenzel M, Hamersky R, Hendrickx F, Herzog F, ST Klota, Koolstra B, Lausch A, Le Coeur D, Liira J, Maelfait JP, Opdam P, Roubalova M, Schermann-Legionnet A, Schermann N, Schmidt T, Smulders MJM, Speelmans M, Simova P, Verboom J, van Wingerden W, Zobel M (2008) Prediction uncertainty of environmental change effects on temperate European biodiversity. Ecol Lett 11:235-244

Fahrig L, Jonsen I (1998) Effect of habitat patch characteristics on abundance and diversity of insects in an agricultural landscape. Ecosystems 1:197-205

Fahrig L, Baundry J, Brotons L, Burel FG, Crist TO, Fuller RJ, Sirami C, Siriwardena GM, Martin JL (2011) Functional landscape heterogeneity and animal biodiversity in agricultural landscapes. Ecol Lett 14:101-112

Gagic V, Tcharntke T, Dormann CF, Gruber B, Wilstermann A, Thies C (2011) Food web structure and biocontrol in a fourtrophic level system across a landscape complexity gradient. Proc R Soc B 278:2946-2953
Geiger F, de Snoo GR, Berendse F, Guerrero I, Morales MB, Oñate JJ, Eggers S, Pärt T, Bommarco R, Bengtsson J, Clement LW, Weisser WW, Olszewski A, Ceryngier P, Hawro V, Inchausti P, Fischer C, Flohre A, Thies C, Tscharntke T (2010a) a) The landscape composition influences farm management effects on farmland birds in winter: a pan-European approach. Agric Ecosyst Environ 139:571-577

Geiger F, Bengtsson J, Berendse F, Weisser WW, Emmerson M, Morales MB, Ceryngier P, Liira J, Tscharntke T, Winqvist C, Eggers S, Bommarco R, Pärt T, Bretagnolle V, Plantegenest M, Clement LW, Dennis C, Palmer C, Oñate J, Guerrero I, Hawro V, Aavik T, Thies C, Flohre F, Hänkei S, Fischer C, Goedhart PW, Inchausti P (2010b) Persistent negative effects of pesticides on biodiversity and biological control potential on European farmland. Basic Appl Ecol 11:97-105

Gianoli E (1999) Within-plant distribution of Rhopalosiphum padi on wheat seedlings is affected by induced responses. Entomol Exp Appl 93:227-230

Holland J, Fahrig L (2000) Effect of woody borders on insect density and diversity in crop fields: a landscape-scale analysis. Agric Ecosyst Environ 78:115-122

Holland JM, Oaten H, Southway S, Moreby S (2008) The effectiveness of field margin enhancement for cereal aphid control by different natural enemy guilds. Biol Control 47:71-76

Holzschuh A, Steffan-Dewenter I, Tscharntke T (2008) Agricultural landscapes with organic crop support higher pollinator diversity. Oikos 117:354-361

Jonsen ID, Fahrig L (1997) Response of generalist and specialist insect herbivores to the landscape spatial structure. Landsc Ecol 12:185-197

Kassen R (2002) The experimental evolution of specialists, generalists, and the maintenance of diversity. J Evol Biol 15:173-190

Kruess A, Tscharntke T (2000) Species richness and parasitism in a fragmented landscape: experiments and field studies with insects on Vicia sepium. Oecologia 122:129-137

Landis DA, Wratten SD, Gurr GM (2000) Habitat management to conserve natural enemies of arthropod pests in agriculture. Annu Rev Entomol 45:175-201

Le Ralec A, Ribulé A, Barragan A, Outreman Y (2011) Host range limitation caused by incomplete host regulation in an aphid parasitoid. J Ins Physiol 57:363-371

Leather SR, Lehti P (1982) Field studies on the factors affecting the population dynamics of the bird cherry-oat aphid, Rhopalosiphum padi (L.) in Finland. Ann Agric Fenniae 21:20-31

Leather SR, Walters KFA, Dixon AFG (1989) Factors determining the pest status of the bird cherry oat aphid, Rhopalosiphum padi (L.) (Hemiptera, Aphididae) in Europe: a study and review. Bull Entomol Res 79:345-360

Mackauer M, Starý P (1967) World Aphidiidae (Hym. Ichneumonoidea). Le François, Paris

Mackauer M, Völkl W (1993) Regulation of aphidiid wasps: does aphidiid foraging behaviour or hyperparasitism limit impact? Oecologia 94:339-350

Marino PC, Landis DA (1996) Effect of landscape structure on parasitoid diversity and parasitism in agroecosystems. Ecol Appl 6:276-284 
Menalled FD, Marino PC, Gage SH, Landis DA (1999) Does agricultural landscape structure affect parasitism and parasitoids diversity? Ecol Appl 9:634-641

Menalled FD, Costamagna AC, Marino PC, Landis DA (2003) Temporal variation in the response of parasitoids to agricultural landscape structure. Agric Ecosyst Environ 96:29-35

Monmany AC, Aide TM (2009) The landscape and community drivers of herbivore parasitism in Northwest Argentina. Agric Ecosyst Environ 134:148-152

Montoya JM, Hawkins BA, Rodriguez MA (2003) Food web complexity and higher-level ecosystem services. Ecol Lett 6:587-593

Müller CB, Adriaanse ICT, Belshaw R, Godfray HCJ (1999) The structure of an aphid - parasitoid community. J Anim Ecol 68:346-370

Öberg S, Ekbom B, Bommarco R (2007) Influence of habitat type and surrounding landscape on spider diversity in Swedish agroecosystems. Agric Ecosyst Environ 122:211-219

Ölmez S, Ulusoy MR (2003) A survey of aphid parasitoids (Hymenoptera: Braconidae: Aphidiinae) in Diyarbakır, Turkey. Phytoparasitica 31:524-528

Östaman Ö, Ekbom B, Bengtsson J (2001) Landscape heterogeneity and farming practice influence biological control. Basic Appl Ecol 2:365-371

Pankanin-Franczyk M (1994) Population dynamics of cereal aphids in relation to short-term predictions of their appearance. Aphids Homopterous Insects 4:95-99

Pareja M, Brown VK, Powell W (2008) Aggregation of parasitism risk in aphid - parasitoid system: effect of plant patch size and aphid density. Basic Appl Ecol 9:701-708

Purtauf T, Dauber J, Wolters V (2005a) The response of carabids to landscape simplification differs between trophic groups. Oecologia 142:458-464

Purtauf T, Roschewitz I, Dauber J, Thies C, Tscharntke T, Wolters V (2005b) Landscape context of organic and conventional farms: influences on carabid beetle diversity. Agric Ecosyst Environ 108:165-174

Rakhshani E, Talebi AA, Manzari S, Rezwani A, Rakhshani H (2006) An investigation on alfalfa aphids and their parasitoids in different parts of Iran, with a key to the parasitoids (Hemiptera: Aphididae; Hymenoptera: Braconidae: Aphidiinae). J Entomol Soc Iran 25:1-14

Rand TA, van Veen FJF, Tscharntke T (2012) Landscape complexity differentially benefits generalized fourth, over specialized third, trophic level natural enemies. Ecography 35:97-104

Rauch G, Weisser WW (2007) Local and spatial dynamics of host - parasitoid system in a field experiment. Basic Appl Ecol 8:89-95

Salvo A, Fenoglio MS, Videla M (2005) Parasitism of a leafminer in managed versus natural habitats. Agric Ecosyst Environ 109:213-220

Schmidt MH, Roschewitz I, Thies C, Tscharntke T (2005) Differential effect of landscape and management on diversity of ground-dwelling farmland spiders. J Appl Ecol 42:281-287

Schüepp C, Herrmann JD, Herzog F, Schmidt-Entling MH (2011) Differential effects of habitat isolation and landscape composition on wasps, bees, and their enemies. Oecologia 165:713-721
Settle WH, Ariawan H, Astuti ET, Cahyana W, Hakim AL, Hindayana D, Lestari AS (1996) Managing tropical rice pests through conservation of generalist natural enemies and alternative prey. Ecology 77:1975-1988

Sigsgaard L (2002) A survey of aphids and aphid parasitoids in cereal fields in Denmark, and the parasitoids' role in biological control. J Appl Entomol 126:101-107

Snyder WE, Ives AR (2003) Interactions between specialist and generalist natural enemies: parasitoids, predators, and pea aphid biocontrol. Ecology 84:91-107

Stilmant D, van Bellinghen C, Hance T, Boivin G (2008) Host specialization in habitat specialists and generalists. Oecologia 156:905-912

Thies C, Tscharntke T (1999) The landscape structure and biological control in agroecosystems. Science 285:893-895

Thies C, Dewenter IS, Tscharntke T (2003) Effects of landscape context on herbivory and parasitism at different spatial scales. Oikos 101:18-25

Thies C, Roschewitz I, Tscharntke T (2005) The landscape context of cereal aphid-parasitoid interactions. Proc R Soc B 272:203-210

Thies C, Hänke S, Scherber C, Bengtsson J, Bommarco R, Clement LW, Ceryngier P, Dennis C, Emmerson M, Gagic V, Hawro V, Liira J, Weisser WW, Winqvist C, Tscharntke $\mathrm{T}$ (2011) The relationship between agricultural intensification and biological control: experimental tests across Europe. Ecol Appl 21:2187-2196

Tscharntke T, Kruess A (1999) Habitat fragmentation and biological control. In: Hawkin BA, Cornell HV (eds) Theoretical approaches to biological control. Cambridge University Press, Cambridge, pp 190-205

Tscharntke T, Klein M, Kruess A, Steffan-Dewenter I, Thies C (2005) Landscape perspectives on agricultural intensification and biodiversity - ecosystem service management. Ecol Lett 8:857-874

Tscharntke T, Bommarco R, Clough Y, Crist TO, Kleijn D, Rand TA, Tylianakis JM, van Nouhuys S, Vidal S (2007) Conservation biological control and enemy diversity on a landscape scale. Biol Control 43:294-309

van Veen FJF, Muller CB, Adriaanse ICT, Godfray HCJ (2002) Spatial heterogeneity in risk of secondary parasitism in a natural population of an aphid parasitoid. J Anim Ecol 71:463-469

Varley GC, Gradwell GR, Hassell MP (1974) Insect population ecology - an analytical approach. University of California Press, Berkeley

Vollhardt IMG, Tscharntke T, Wäckers FL, Bianchi FJJA, Thies C (2008) Diversity of cereal aphid parasitoids in simple and complex landscapes. Agric Ecosyst Environ 126:289-292

Weibull AC, Bengtsson J, Nohlgren E (2000) Diversity of butterflies in the agricultural landscape: the role of farming system and landscape heterogeneity. Ecography 23:743-750

Violetta Hawro is interested in ecology and taxonomy of aphid parasitoids.

Piotr Ceryngier studies focus on the ecology of natural enemies of aphids and aphidophagous insects. 
Teja Tscharntke is interested in the biodiversity and ecosystem services in temperate and tropical landscapes.

Carsten Thies is a researcher in Natural Resources Management, with emphasis on landscape ecology and organism-space interactions.

Vesna Gagic is a researcher at the Swedish University of Agricultural Sciences (SLU), Department for Ecology working in the improvement of ecosystem services.

Jan Bengtsson investigates the composition of ecological communities and ecosystem processes, biodiversity and ecosystem services, soil and landscape ecology, farming systems and sustainable agriculture.

Riccardo Bommarco is interested in the landscape ecology of insects and plants in agricultural landscapes.
Camilla Winqvist is involved in ecological research focusing on agricultural intensification, landscape ecology and ecosystem services.

Wolfgang W. Weisser studies the relationship between land use, biodiversity and ecosystem services.

Lars W. Clement focuses on agricultural land use and its impact on the biocontrol of aphids.

George Japoshvili is a taxonomist of parasitic wasps belonging to the families Encyrtidae and Aphelinidae.

Werner Ulrich looks at spatial distributions of insect and plant species and patterns of species co-occurrence in space and time from an evolutionary perspective. 